\title{
Exisulind and CP248 induce growth inhibition and apoptosis in human esophageal adenocarcinoma and squamous carcinoma cells
}

\author{
Andrew K. Joe ${ }^{1,2}$, Hui Liu ${ }^{1}$, Danhua Xiao ${ }^{1}$, Jae-Won Soh ${ }^{1}$, John T. Pinto ${ }^{3}$, David G. Beer ${ }^{4}$, Gary \\ A. Piazza ${ }^{5}$, W. Joseph Thompson ${ }^{5}$, and I. Bernard Weinstein ${ }^{1,2}$ \\ ${ }^{1}$ Herbert Irving Comprehensive Cancer Center, ${ }^{2}$ Department of Medicine, College of Physicians \& Surgeons of Columbia \\ University, New York, NY, ${ }^{3}$ American Health Foundation, Valhalla, NY, ${ }^{4}$ University of Michigan, Ann Arbor, MI, and \\ ${ }^{5}$ Cell Pathways, Inc., Horsham, PA, U.S.A. \\ Correspondence to Andrew K. Joe, Herbert Irving Comprehensive Cancer Center, 701 West 168th Street, HHSC-1509, New York, NY 10032, U.S.A. \\ Tel.: +1-212-305-6916. Fax: +1-212-305-6889. E-mail: akj3@columbia.edu \\ (Received March 31, 2003; accepted April 1, 2003; sponsored by I. Bernard Weinstein)
}

We examined the effects of exisulind (sulindac sulfone) and a potent derivative CP248 on the Barrett's esophagus (BE)-related adenocarcinoma cell lines Seg-1 and Bic-1, and on HCE7 esophageal squamous carcinoma cells. Marked growth inhibition and apoptosis occurred in all cell lines with $\mathrm{IC}_{50}$ values of $100-300 \mu \mathrm{M}$ for exisulind and $100 \mathrm{nM}$ for CP248. Bic- 1 and HCE7 cells were more sensitive to the growth inhibitory properties of exisulind. Treatment of all cell lines with CP248 for $24 \mathrm{~h}$ increased the proportion of cells in mitosis. Exisulind had no effect on cell-cycle progression. Treatment with either compound induced rapid activation of the c-Jun $\mathrm{NH}_{2}$-terminal kinase 1 (JNK1), suggesting that JNK1 activation plays a role in the induction of apoptosis by these compounds. Only Seg-1 cells expressed a detectable basal level of cyclooxygenase-2 (cox-2), providing further evidence that cox-2 is not the critical target for the growth inhibitory and apoptotic effects of these compounds. Cellular levels of reduced glutathione (GSH) increased approximately five-fold in all cell lines after $24 \mathrm{~h}$ of treatment with either compound. These studies provide support for the use of exisulind in BE chemoprevention trials, and of exisulind or CP248 in the therapy of patients with esophageal carcinoma.

Keywords: Barrett's esophagus, chemoprevention, CP248, exisulind

(C) 2003 Blackwell Publishing Inc

\section{INTRODUCTION}

Barrett's esophagus (BE) is a premalignant lesion that develops usually as a consequence of chronic gastroesophageal reflux disease (1). The risk of esophageal adenocarcinoma in this population is comparable to the risk of colon cancer in patients with ulcerative colitis. During the past 15 years, the incidence of $\mathrm{BE}$-associated adenocarcinoma (BAA) has greatly increased in both North America and Europe $(1,2)$. For this reason, there is considerable interest in promoting surveillance of patients with $\mathrm{BE}$ to detect early-stage cancers, in developing molecular markers to predict cancer risk, and in developing novel approaches to the prevention and treatment of BAA. At the present time, there are no proven approaches to chemoprevention of this disease.

Preclinical and clinical evidence support a role for nonsteroidal anti-inflammatory drugs (NSAIDs) in the prevention of colorectal and other gastrointestinal malignancies (3-5). Exisulind (sulindac sulfone) is a metabolite of the NSAID sulindac, and CP248 is a highly potent synthetic analog of exisulind (6). Previous investigations have demonstrated significant anticancer activities of

Journal of Experimental Therapeutics and Oncology Vol. $3 \quad 2003 \quad 83$ 
these compounds in a variety of human cancer cell lines, including colon, breast, and prostate cancer cell lines (5-10). However, there are no published studies of their effects in esophageal cancer cells. Exisulind and CP248 belong to a unique group of compounds that induce apoptosis through a recently described novel signaling pathway. In SW480 colon cancer cells, these drugs increase cellular levels of cyclic GMP (cGMP) through the inhibition of cGMP phosphodiesterases $(2,5)$, leading to the activation of protein kinase $G$ (PKG). The subsequent induction of apoptosis appears to be due to PKG-mediated degradation of $\beta$-catenin and activation of JNK1, but additional targets may also play a role (11-13). CP248 can also induce a marked cell-cycle arrest in mitosis, by interfering with microtubule polymerization (14). In contrast to sulindac and other NSAIDs, neither exisulind nor CP248 inhibits cyclooxygenase activity. Furthermore, exisulind and CP248 appear to act independently of p53 $(5,6)$ and are not inhibited by bcl-2 overexpression (6). Exisulind also inhibits chemical carcinogenesis and tumor growth in various animal models $(5,8,15)$. Exisulind is currently being studied as a chemoprevention agent for patients with familial adenomatous polyposis (FAP) who are at risk for the development of colon cancer (16). It is also being studied for use in combination with cytotoxic chemotherapy agents for the management of patients with various types of advanced malignancies (17).

In view of the above findings, exisulind is a potential chemoprevention agent for patients with BE. As described above, this population represents a unique group of patients who are at risk for cancer and who undergo routine surveillance during which esophageal tissue can be obtained to monitor the effects of various types of treatment. Therefore, we initiated the present studies to provide support for the use of this drug in the prevention and treatment of BAA. For this purpose, we utilized two cell lines originally derived from BAA, Seg-1 and Bic-1, and for comparison, we also included the human esophageal squamous carcinoma cell line HCE7. Because of its unique properties, we also examined in parallel with exisulind, the effects of CP248 on cell proliferation, apoptosis, and specific biomarkers.

\section{MATERIALS AND METHODS}

\section{Compounds and Antibodies}

Exisulind and CP248 were obtained from Cell Pathways, Inc (Horsham, PA). The compounds were supplied in powder form, dissolved in dimethylsulfoxide (DMSO; Sigma, St. Louis, MO), and added directly to cellculture medium at a final concentration of $0.1 \%$ DMSO. The following primary antibodies were obtained: cyclin D1 (Upstate Biotechnology, Lake Placid, NY), p2 ${ }^{\text {Kip1 }}$ (Santa Cruz, Santa Cruz, CA), cox-2 (Oxford Biomed, Oxford, MI), PKG (Calbiochem, San Diego, CA), and actin (Sigma). Propidium iodide (PI) was obtained from Sigma.

\section{Cell Culture}

The BAA cell lines Seg-1 and Bic-1, were developed from patients with BAA by Dr. David G. Beer (University of Michigan, Ann Arbor, MI) and grown in Dulbecco's modified Eagle's medium (Life Technologies, Grand Island, NY) supplemented with 10\% fetal bovine serum (FBS) (Life Technologies). HCE7 human esophageal squamous carcinoma cells $(18,19)$ were grown in RPMI1640 medium (Life Technologies) with 10\% FBS. All of the cell lines were maintained at $37^{\circ} \mathrm{C}$ in a $5 \% \mathrm{CO}_{2}$ atmosphere.

\section{Cell-Proliferation Assays}

Cell proliferation was measured using the MTT Cell Proliferation Kit I (BoehringerMannheim, Indianapolis, IN), which colorimetrically measures a purple formazan compound produced by viable cells. Cells were plated in flat-bottomed, 96-well microtiter plates $\left(4 \times 10^{3}\right.$ cells $/ 6.4 \mathrm{~mm}$-diameter well). After $12-24 \mathrm{~h}$, cells were treated with DMSO $(0.1 \%)$ or increasing doses of exisulind or $\mathrm{CP} 248$. After $48 \mathrm{~h}$ of treatment, cells were treated with $10 \mu \mathrm{l}$ of the MTT reagent for $4 \mathrm{~h}$ at $37^{\circ} \mathrm{C}$, and then with $100 \mu \mathrm{l}$ of solubilization solution at $37^{\circ} \mathrm{C}$ overnight. The quantity of formazan product was measured using a spectrophotometric microtiter plate reader (Dynatech Laboratories, Alexandria, VA) at $570 \mathrm{~nm}$ wavelength. Results were expressed as percent growth, with $100 \%$ representing 
control cells treated with DMSO alone. All experiments were performed in triplicate.

\section{Apoptosis Assays}

The percent of cells actively undergoing apoptosis was determined using annexin V-phycoerythrin (PE)-based immunofluorescence, as previously described (20). Briefly, cells were plated in $10-\mathrm{cm}$ culture dishes at concentrations to yield $60-70 \%$ confluence within $24 \mathrm{~h}$. Cells were then treated with DMSO $(0.1 \%)$, exisulind $(300 \mu \mathrm{M})$ or $\mathrm{CP} 248$ $(200 \mathrm{nM})$. After $48 \mathrm{~h}$ of treatment, both adherent and floating cells were harvested and then double-labeled with annexin $\mathrm{V}-\mathrm{PE}$ and 7-aminoactinomycin (7-AAD) (PharMingen, San Diego, CA), as described by the manufacturer. Cells were analyzed using a FACScan instrument equipped with FACStation running Cell Quest software (Becton Dickinson, San Jose, CA). All experiments were performed in duplicate.

\section{Cell-Cycle Distribution Analysis}

PI staining was used to analyze DNA content. Cells were plated in $10-\mathrm{cm}$ culture dishes at concentrations to yield $60-70 \%$ confluence within $24 \mathrm{~h}$. Cells were then treated with DMSO $(0.1 \%)$, exisulind $(300 \mu \mathrm{M})$, or CP248 $(200 \mathrm{nM})$. After a 24-h treatment, both adherent and floating cells were harvested and labeled with PI, as previously described (6). Briefly, cells were resuspended in phosphatebuffered saline (PBS), fixed with $70 \%$ ethanol, labeled with PI $(0.05 \mathrm{mg} / \mathrm{ml})$, incubated at room temperature in the dark for $30 \mathrm{~min}$, and filtered through $41-\mu \mathrm{m}$ spectra/mesh nylon filters (Spectrum, Rancho Dominguez, CA). DNA content was then analyzed using a FACScan instrument equipped with FACStation running Cell Quest software. All experiments were performed in triplicate.

\section{Assay to Identify Cells in Mitosis}

An assay, which measures the binding of an antibody, anti-MPM2 (mitotic phosphoprotein 2), to a mitosis-specific phosphorylated epitope MPM2 was used to determine the proportion of cells undergoing mitosis, as described previously (21). Cells were plated in $10-\mathrm{cm}$ culture dishes at concentrations to yield $60-70 \%$ confluence within $24 \mathrm{~h}$. Cells were treated with either DMSO $(0.1 \%)$ or CP248 $(200 \mathrm{nM})$. After $24 \mathrm{~h}$ of treatment, cells were harvested and treated with $70 \%$ ethanol. Cells were resuspended in PBS containing $2 \% \mathrm{FBS}$, incubated with the primary anti-MPM2 antibody (Upstate Biotechnology) for $30 \mathrm{~min}$ at room temperature in the dark, then with fluorescein isothiocyanate (FITC)labeled antimouse antibody (Rockland, Gilbertsville, PA) for 30 min in the dark at room temperature, and finally with PI $(0.01 \mathrm{mg} /$ $\mathrm{ml})$. Prior to analysis, samples were filtered through $41-\mu \mathrm{m}$ spectra/mesh filters (Spectrum). DNA content and fluorescein activity were then analyzed using a FACScan instrument equipped with FACStation running Cell Quest software (Becton Dickinson). All experiments were performed in triplicate.

\section{JNK1 Kinase Assays}

The methods for in vitro JNK1 kinase assays have been previously described in detail (12). Briefly, Seg-1 cells were plated in $10-\mathrm{cm}$ culture dishes at concentrations to yield $60-70 \%$ confluence within $24 \mathrm{~h}$. Cells were treated with $0.1 \%$ DMSO, $300 \mu \mathrm{M}$ exisulind, or $200 \mathrm{nM} \mathrm{CP} 248$ and harvested after 2 and $24 \mathrm{~h}$. After cell lysis, JNK1 was immunoprecipitated with an anti-JNK1 antibody (Santa Cruz) for $2 \mathrm{~h}$ and assayed for in vitro kinase activity with GST-c-Jun (1-79) (New England Biolab, Beverly, MA) as the substrate in a kinase reaction buffer for $20 \mathrm{~min}$. The reaction mixture was then subjected to $10 \%$ SDS-PAGE. The extent of protein phosphorylation was determined using autoradiography. Experiments were performed in duplicate.

\section{Protein Extraction and Western Blotting}

The methods for protein extraction and Western blot analysis have been described previously (22). Briefly, cells were treated with $0.1 \%$ DMSO (negative control), exisulind $(300 \mu \mathrm{M})$, or $\mathrm{CP} 248(200 \mathrm{nM})$. Experiments involving cox-2 analysis also included cells treated with 12-O-tetradecanoylphorbol13 -acetate (TPA) $(100 \mathrm{ng} / \mathrm{ml})$ for $5 \mathrm{~h}$ (positive control). After $24-48 \mathrm{~h}$ of treatment, cell lysates were prepared, and $60-100 \mu \mathrm{g}$ of protein was separated by SDS-PAGE (10\%). After transfer 
to nitrocellulose membranes (Millipore, Bedford, MA), blots were blocked with 5\% milk protein, incubated for $1 \mathrm{~h}$ with the indicated primary antibody, and then reincubated for $1 \mathrm{~h}$ with the corresponding horseradish peroxidase-conjugated secondary antibody. Protein-antibody complexes were detected by the enhanced chemiluminescence system (Amersham, Piscataway, NJ). Immunoblotting for actin was performed to verify equivalent amounts of loaded protein.

\section{GSH Induction}

Cells were plated in $10-\mathrm{cm}$ culture dishes at concentrations to yield $60-70 \%$ confluence within $24 \mathrm{~h}$. Cells were treated with $0.1 \%$ DMSO, exisulind $(300 \mu \mathrm{M})$, or CP248 $(200 \mathrm{nM})$. Cells were harvested after $3 \mathrm{~h}$ and $24 \mathrm{~h}$ of treatment, and then lysed in $200 \mathrm{mM}$ methane sulfonic acid. Precipitates were dissolved in $0.1 \mathrm{~N} \mathrm{NaOH}$. Concentrations of GSH were measured using a Perkin-Elmer high performance liquid chromatography (HPLC) equipped with a 4-channel coulometric array detector (ESA, Inc., Chelmsford, MA). The final concentrations of GSH were reported as $\mathrm{nmol} / \mathrm{mg}$ protein. (For additional details, please refer to (23)).

\section{Statistical Analyses}

Data are expressed as mean $\pm \mathrm{SD}$. Comparisons between DMSO-treated control cells and exisulind- or CP248-treated cells were made using the Student's $t$ test. Differences between groups of $P<0.01$ or $P<0.001$ were considered statistically significant.

\section{RESULTS}

\section{Growth Inhibition by Exisulind and CP248}

To demonstrate the antitumor activities of exisulind and CP248 in human esophageal carcinoma cells, we investigated their effects on cell growth in cell lines of different histologic subtypes. Two BAA cell lines Seg-1 and Bic-1, were compared with the HCE7 esophageal squamous carcinoma cell line. Exponentially dividing cells were treated with increasing concentrations of either exisulind
$(50-500 \mu \mathrm{M})$ or CP248 $(25-400 \mathrm{nM})$. Both exisulind and CP248 caused statistically significant growth inhibition, in a dosedependent fashion, in all three cell lines after $48 \mathrm{~h}$ of treatment, with $\mathrm{IC}_{50}$ values of 150-300 $\mu \mathrm{M}$ and 50-100 nM, respectively (Figure 1). Bic-1 and HCE7 cells were about twice as sensitive to growth inhibition by exisulind than Seg-1 cells. CP248 was about 1000 times more potent than exisulind, and all three cell lines appeared to be equally sensitive to this compound.

\section{Apoptosis Induction by Exisulind and CP248}

Because exisulind and CP248 inhibited the growth of the three esophageal cancer cell lines, we determined whether these compounds also induced apoptosis. For these and most of our subsequent studies, we used doses of exisulind and CP248 that were at least one to two times the $\mathrm{IC}_{50}$ value for each cell type $(300 \mu \mathrm{M}$ exisulind and $200 \mathrm{nM}$ CP248). When the three esophageal cancer cells were treated for $48 \mathrm{~h}$, there was a marked induction of apoptosis. Results with HCE7 cells are shown in Figure 2. The percentage of apoptotic cells increased from $5.9 \%$ in control DMSO-treated cells to 15.1 and $24.2 \%$ after treatment with exisulind and CP248, respectively. Similarly, treatment with exisulind or CP248 for $48 \mathrm{~h}$ induced apoptosis in Bic-1 cells (from a control value of 8.2 to $18.6 \%$ and $21.0 \%$, respectively) and in Seg- 1 cells (from a control value of 0.4 to $6.3 \%$ and $53.9 \%$, respectively) (data not shown). Therefore, our studies demonstrate that Seg-1 cells are less sensitive than Bic-1 and HCE7 cells to both growth inhibition (Figure 1A) and apoptosis induction by exisulind. Exisulind and CP248 also induced apoptosis in each of the cell lines after $24 \mathrm{~h}$ of treatment, although to an extent less than that observed after the 48-h treatment (data not shown). Our results are consistent with previous studies, which demonstrated that exisulind and CP248 induce apoptosis in colon and prostate cancer cell lines $(6,11,12)$.

\section{Effects on Cell-Cycle Progression}

We examined the effects of exisulind and $\mathrm{CP} 248$ on cell-cycle progression in 

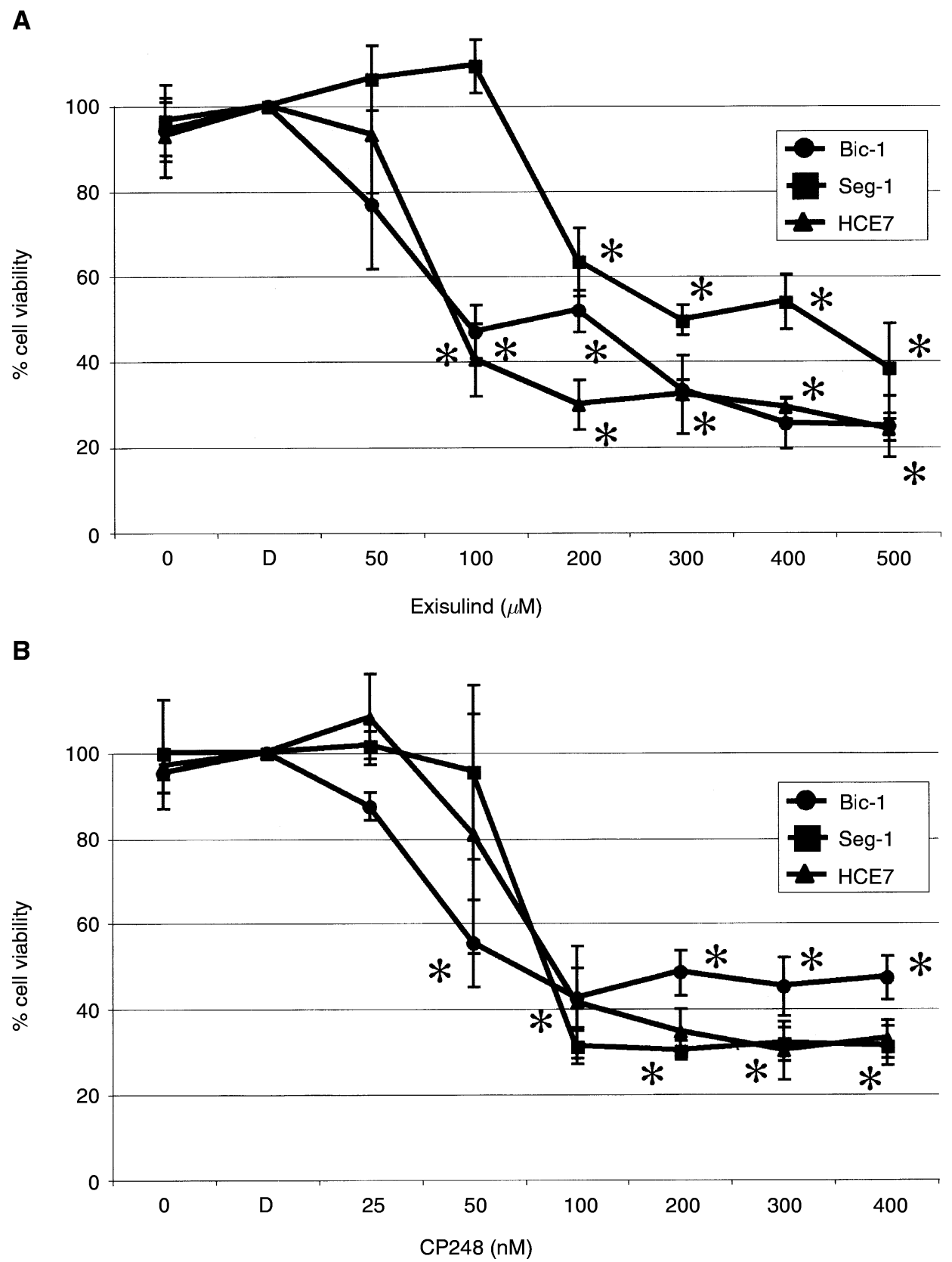

Figure 1. Growth inhibition of esophageal carcinoma cells after treatment with exisulind or CP248 for $48 \mathrm{~h}$. Exponentially dividing cells were treated with increasing concentrations of exisulind (A) or CP248 (B). Cell viability was determined using the MTT assay. The percent of growth was calculated with $100 \%$ representing control cells treated with $0.1 \%$ dimethylsulfoxide (DMSO) alone. The results are the means \pm SD from triplicate experiments $\left({ }^{*}, P<0.01\right)$.

exponentially dividing cultures of these three cell lines. Subconfluent cultures of cells were treated with DMSO alone, exisulind $(300 \mu \mathrm{M})$, or CP248 $(200 \mathrm{nM})$. Since we were interested in evaluating the distribution of actively dividing cells prior to the induction of extensive apoptosis, we harvested the cells at $24 \mathrm{~h}$, rather than at $48 \mathrm{~h}$. The cells were then labeled with PI and analyzed by DNA flow cytometry. Representative DNA histograms for the Bic-1 cells are shown in Figure 3. Similar results were seen with Seg-1 and HCE7 cells (Table 1). In all three cell lines, CP248 induced a striking accumulation 
Joe $A K$ et al.
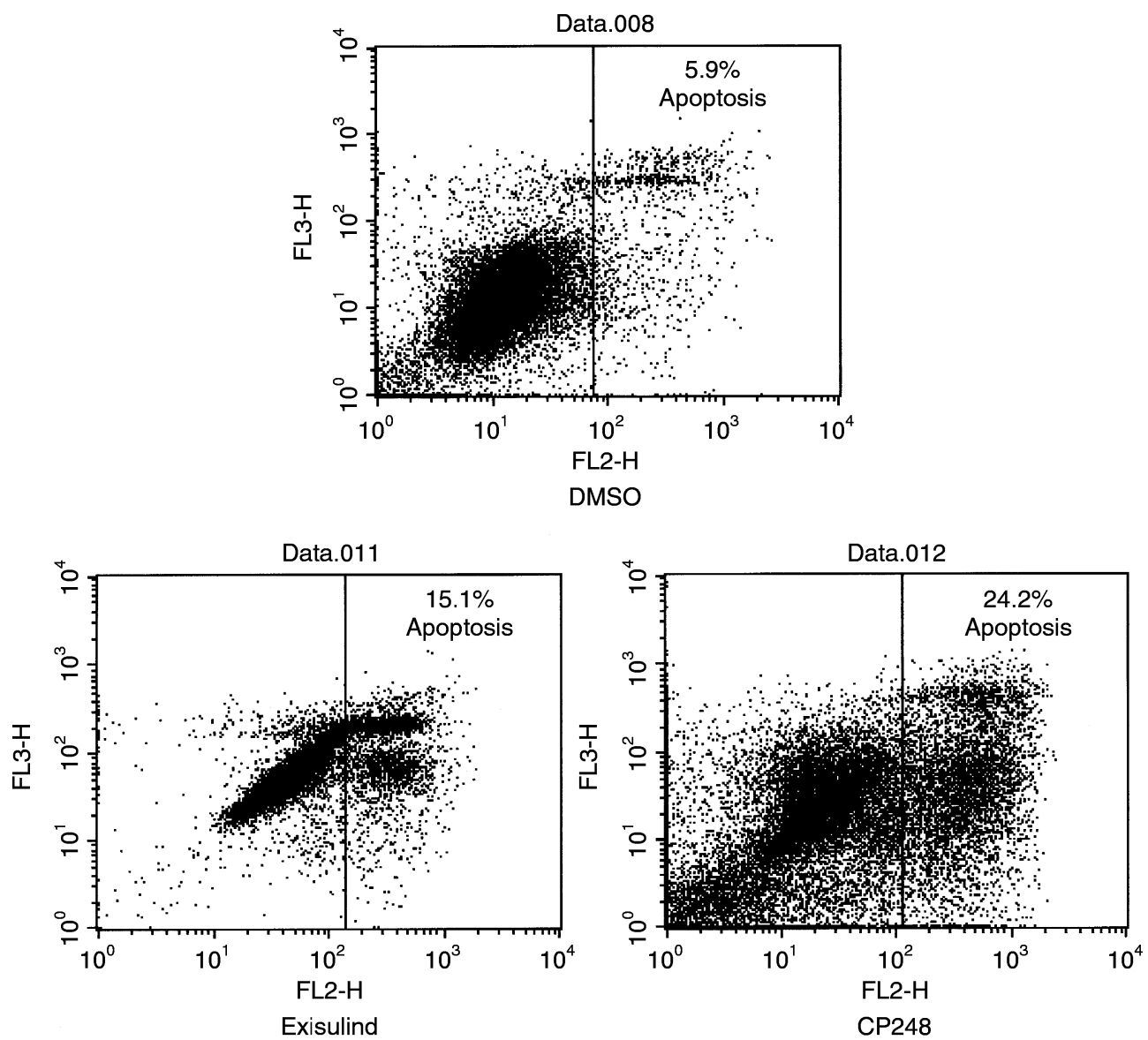

Figure 2. Apoptosis induction. HCE7 cells were treated with $0.1 \%$ dimethylsulfoxide (DMSO), $300 \mu \mathrm{M}$ exisulind, or $200 \mathrm{nM} \mathrm{CP248}$ for $48 \mathrm{~h}$. Cells were double-stained with annexin V-phycoerythrin and 7-aminoactinomycin and analyzed for apoptosis by DNA flow cytometry. The data indicate the percentage of cells, which are annexin V-positive (apoptotic). Similar results were obtained in duplicate experiments.

of cells in the G2/M phase of the cell cycle. In contrast, exisulind did not induce significant changes in cell-cycle distribution (Figure 3 and Table 1).

Because of CP248's striking ability to arrest esophageal cancer cells in the G2/M phase, it was of interest to determine whether the CP248-treated cells were specifically arrested in mitosis, and to confirm that treated cells were not simply tetraploid cells in the G1 phase. Cells that were treated with either $0.1 \%$ DMSO or $200 \mathrm{nM}$ CP248 were harvested after $24 \mathrm{~h}$, dual-labeled with PI and a FITC-conjugated monoclonal antibody directed against the MPM2 protein, and then analyzed by flow cytometry. MPM2 labeling specifically identifies cells in mitosis (21). Seg-1 cells treated with DMSO alone displayed minimal (2\%) MPM2 labeling (Figure 4). However, in the CP248-treated cells, about $50 \%$ of the $\mathrm{G} 2 / \mathrm{M}$ arrested cells were MPM2-positive. Therefore, CP248 causes esophageal cancer cells to arrest in mitosis. Similar results were observed in CP248-treated HCE7 and Bic-1 cells (data not shown).

\section{JNK1 Activation}

Our previous studies have shown that when human colon cancer cells are treated with exisulind or CP248, there is rapid activation of the signaling molecule JNK1, and that this activation may play a critical role in the induction of apoptosis by these and related compounds (12). Therefore, we investigated whether rapid activation of JNK1 also occurs when esophageal cancer cells are treated with exisulind or CP248. Seg-1 cells were 


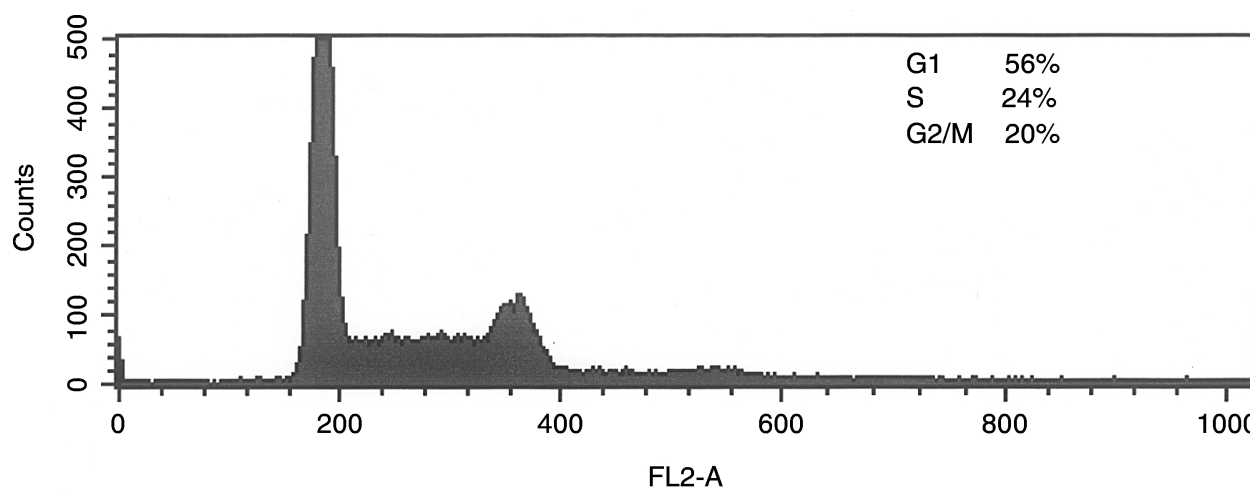

DMSO

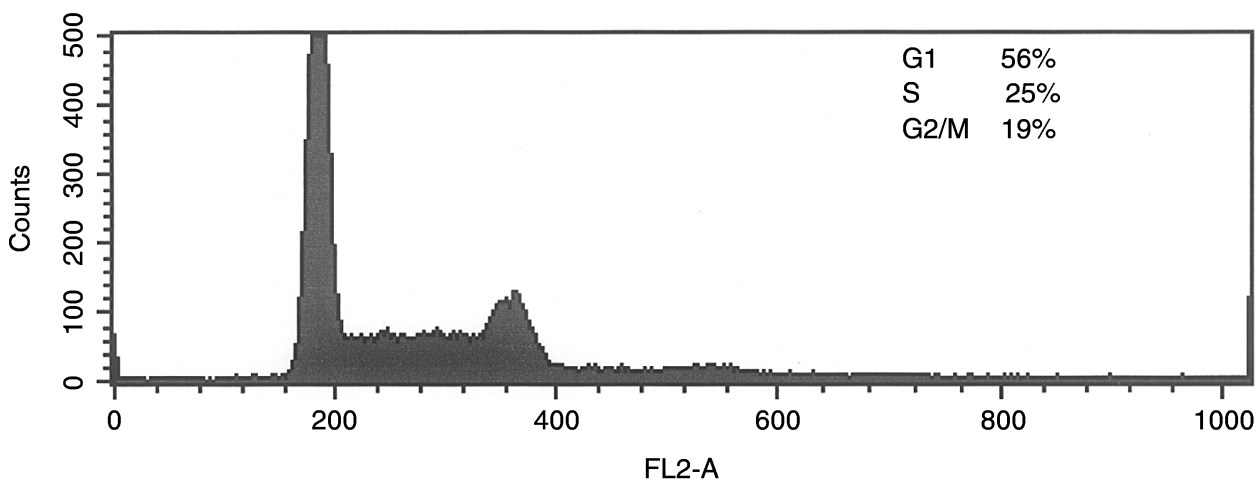

Exisulind

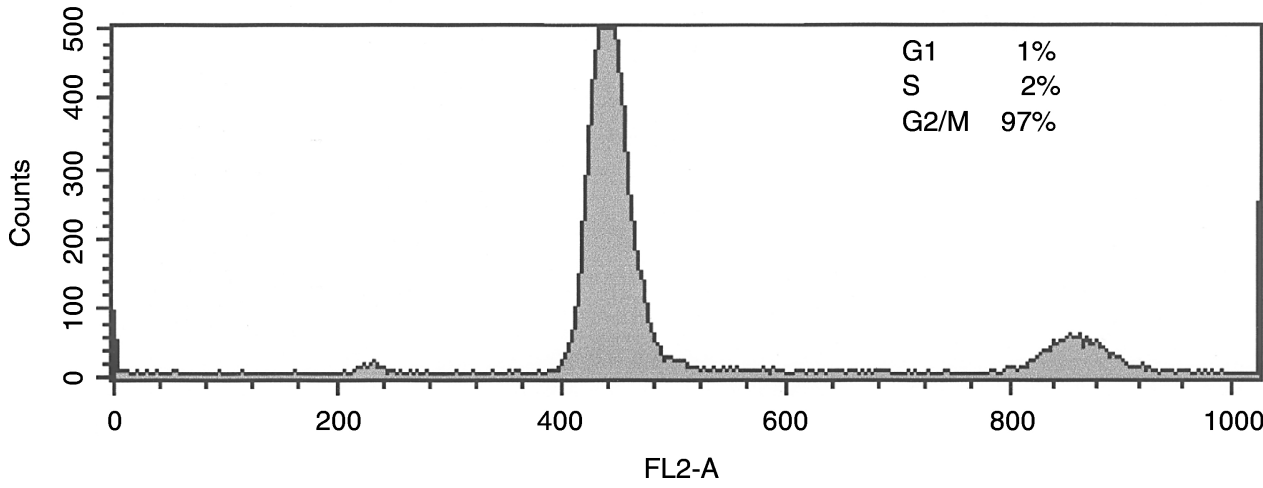

CP248

Figure 3. Cell-cycle analysis of Bic-1 cells after treatment with $0.1 \%$ dimethylsulfoxide (DMSO), $300 \mu \mathrm{M}$ exisulind, or $200 \mathrm{nM}$ CP248. After $24 \mathrm{~h}$ of treatment, cells were labeled with propidium iodide $(\mathrm{PI})$ and analyzed by DNA flow cytometry. The data indicate the percentage of cells in each phase of the cell cycle. Similar results were obtained in triplicate experiments.

treated with $0.1 \%$ DMSO, $300 \mu \mathrm{M}$ exisulind or $200 \mathrm{nM} \mathrm{CP248}$ and assayed for JNK1 activation after 2 and $24 \mathrm{~h}$ of treatment (Figure 5). Endogenous JNK1 was immunoprecipitated with an anti-JNK1 antibody, and in vitro kinase assays were performed with GST-c-Jun as the substrate. Treatment of Seg-1 cells with both exisulind and CP248 led to rapid (within $2 \mathrm{~h}$ ) activation of JNK1. As previously seen with colon cancer cells (12), CP248 activated JNK1 more strongly than did exisulind. Moreover, JNK1 activa- tion was sustained for at least $24 \mathrm{~h}$ with CP248.

\section{Cox-2 Induction in Seg-1 Cells}

Because of the interest in increased cox-2 expression in a variety of human cancers (24-27), and the fact that a number of NSAIDs inhibit cox-2 enzymatic activity, we examined this marker in our esophageal cancer cell lines. Seg-1 cells were treated with $0.1 \%$ DMSO (negative control), TPA 
Table 1. Cell cycle distribution of esophageal cancer cell lines after treatment for $24 \mathrm{~h}$ with dimethyl sulfoxide DMSO (0.1\%), exisulind $(300 \mu \mathrm{M})$, or CP248 (200 nM).

\begin{tabular}{lcccc}
\hline \multirow{2}{*}{ Cell Line } & & \multicolumn{3}{c}{ Distribution (\% cells)* } \\
\cline { 3 - 5 } & & G1 & S & G2/M \\
\hline Bic-1 & DMSO & $54.3 \pm 3.6$ & $25.7 \pm 2.8$ & $19.9 \pm 1.6$ \\
& Exisulind & $56.8 \pm 3.0$ & $21.8 \pm 2.4$ & $21.3 \pm 1.1$ \\
& CP248 & $1.9 \pm 0.4 \dagger$ & $2.5 \pm 0.3 \dagger$ & $95.7 \pm 0.6 \dagger$ \\
Seg-1 & DMSO & $59.3 \pm 2.9$ & $18.0 \pm 3.5$ & $22.7 \pm 1.5$ \\
& Exisulind & $60.2 \pm 0.8$ & $15.8 \pm 1.9$ & $24.0 \pm 1.1$ \\
& CP248 & $7.0 \pm 1.7 \dagger$ & $9.1 \pm 2.2$ & $83.9 \pm 0.8 \dagger$ \\
HCE7 & DMSO & $48.2 \pm 1.8$ & $21.3 \pm 0.9$ & $30.4 \pm 2.4$ \\
& Exisulind & $57.2 \pm 3.6$ & $19.0 \pm 4.5$ & $23.7 \pm 1.0$ \\
& CP248 & $4.4 \pm 0.1 \dagger$ & $9.6 \pm 0.7 \dagger$ & $86.0 \pm 0.8 \dagger$ \\
\hline
\end{tabular}

${ }^{*} D N A$ content was analyzed using PI staining and DNA flow cytometry (Figure 3). The data indicate the percent of cells in each phase of the cell cycle. The values are the mean $\pm S D$ of triplicate assays.

$\dagger P<0.001$.

(100 ng/ml, positive control for induction of cox-2 (28)), exisulind $(300 \mu \mathrm{M})$, or $\mathrm{CP} 248$ $(200 \mathrm{nM})$. After $5 \mathrm{~h}$ of treatment with TPA or $48 \mathrm{~h}$ of treatment with either exisulind or CP248, cell extracts were analyzed for levels of cox- 2 by Western blotting (Figure 6). Seg-1 cells expressed a basal level of cox-2, and as expected TPA markedly induced the level of its expression. Surprisingly, both exisulind and CP248 also induced the expression of cox-2. However, Bic-1 and HCE7 cells did not express detectable basal levels of cox-2, nor was cox-2 induced by TPA, exisulind, or CP248 in these cell lines (data not shown).

\section{Induction of Reduced Glutathione}

Glutathione-S-transferase (GST) and glutathione play important roles in cancer predisposition and carcinogen detoxification (29). Therefore, it was of interest to measure the effects of exisulind and CP248 on cellular levels of GSH using an HPLC-based assay. Seg- 1 cells were treated with $0.1 \%$ DMSO, exisulind $(300 \mu \mathrm{M})$, or CP248 $(200 \mathrm{nM})$. Cells were harvested after 3 and $24 \mathrm{~h}$ of treatment, and total cellular concentrations of GSH were measured using a Perkin-Elmer HPLC. Exisulind and CP248 markedly induced cellular levels of GSH after 3 and $24 \mathrm{~h}$ of treatment, with a two- to 2.5-fold increase at $3 \mathrm{~h}$ and a six-to eight-fold increase at $24 \mathrm{~h}$ (Figure 7). Both compounds also caused similar
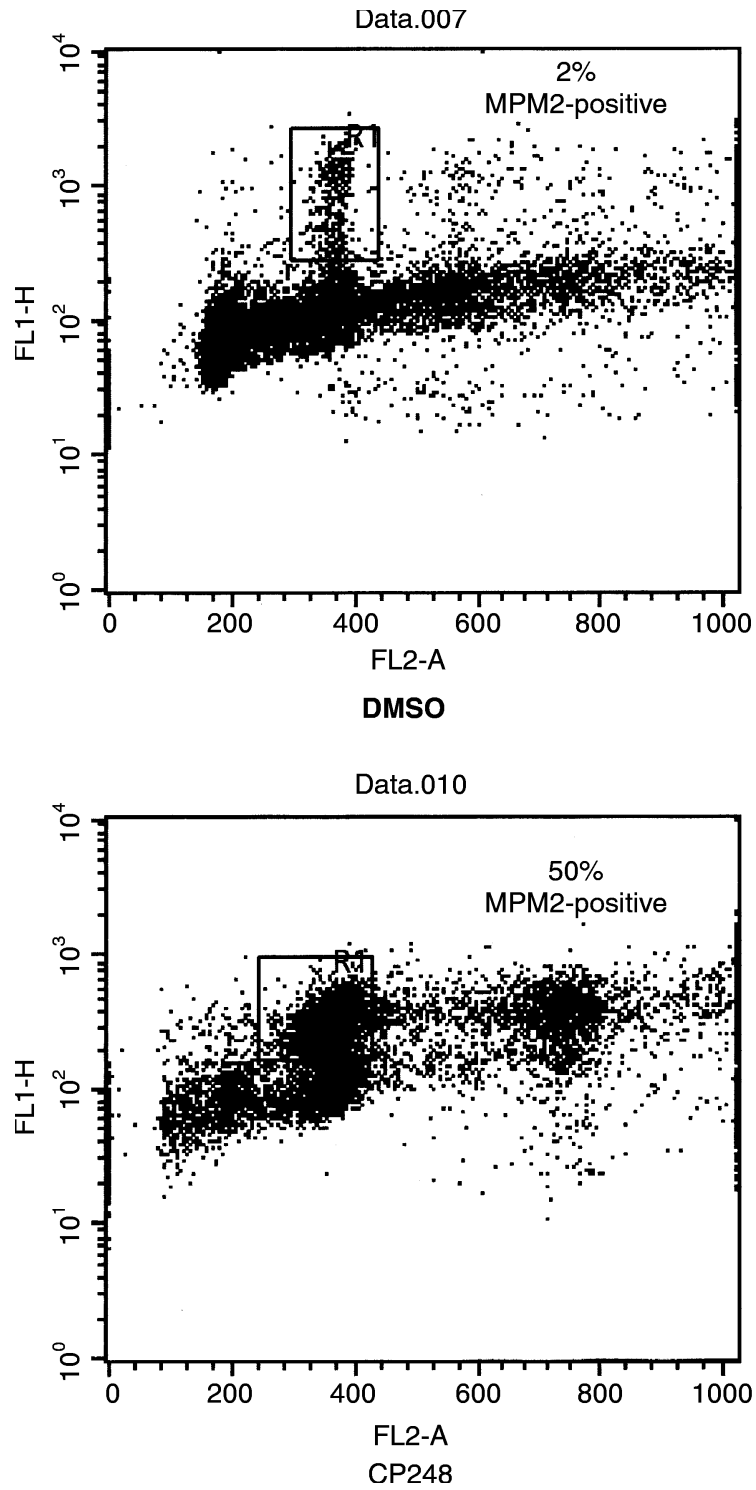

Figure 4. Analysis for percent of Seg-1 cells in mitosis (mitotic phosphoprotein 2 (MPM2)-positive) after treatment with $0.1 \%$ dimethylsulfoxide (DMSO) or $200 \mathrm{nM} \mathrm{CP248.} \mathrm{After} 24 \mathrm{~h}$ of treatment, cells were labeled with propidium iodide $(\mathrm{PI})$ and the MPM2 antibody as described in Materials and Methods, and analyzed by DNA flow cytometry. Similar results were obtained in triplicate experiments.

increases in GSH in Bic-1 and HCE7 cells (data not shown).

\section{DISCUSSION}

The purpose of this study was to provide support for the development of exisulind and related drugs as chemopreventive and anticancer agents in patients with $\mathrm{BE}$ and 


\section{$2 \mathrm{~h} \quad 24 \mathrm{~h}$

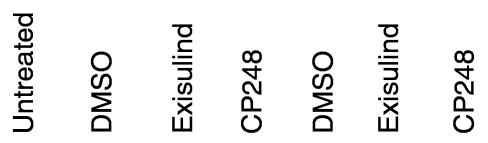

Gst-c-Jun

Figure 5. Activation of c-jun $\mathrm{NH}_{2}$-terminal kinase 1 (JNK1) in Seg-1 esophageal cancer cells. Seg-1 cells were treated with $0.1 \%$ dimethylsulfoxide (DMSO), $300 \mu \mathrm{M}$ exisulind, or $200 \mathrm{nM}$ CP248 for 2 or $24 \mathrm{~h}$. In vitro JNK1 activity was measured as described in Materials and Methods.

esophageal cancer, respectively. Both exisulind and a potent derivative CP248 were previously shown to induce growth inhibition and apoptosis in several human cancer cell lines, including breast, colon, and prostate cancer cell lines $(6,9,12)$ (and unpublished studies). However, these compounds had not been previously studied in esophageal cancer cell lines. Our results indicate that exisulind and $\mathrm{CP} 248$ display strong antiproliferative activity in both the BAA cell lines Seg-1 and Bic-1, and the esophageal squamous carcinoma cell line HCE7. Both compounds caused a dose-dependent inhibition of growth in all three cell lines with $\mathrm{IC}_{50}$ values of about $150-300 \mu \mathrm{M}$ and $50-100 \mathrm{nM}$ for exisulind and CP248, respectively (Figure 1). These values are similar to those found with other human cancer cell lines $(6,11,12)$, although it appears that the Seg-1 cell line may be less sensitive than the Bic-1 and HCE7 cell lines to the growth inhibitory effects of exisulind (Figure 1). As previously seen with other types of cancer cell lines $(6,12)$, exisulind and CP248 also induced apoptosis in both the adenocarcinoma and squamous cell carcinoma esophageal cancer

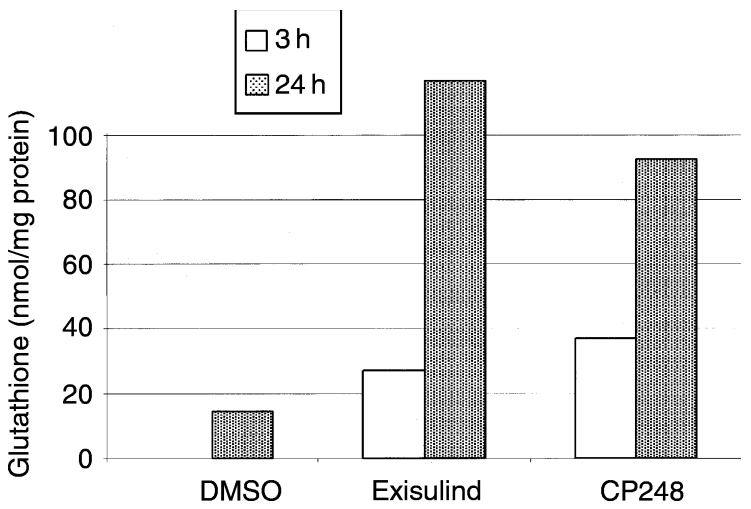

Figure 7. Glutathione induction in Seg-1 cells after treatment with exisulind or CP248. Seg-1 cells were treated with $0.1 \%$ dimethylsulfoxide (DMSO) for $24 \mathrm{~h}$ and $300 \mu \mathrm{M}$ exisulind or $200 \mathrm{nM}$ CP248 for 3 or $24 \mathrm{~h}$. Cellular levels of reduced glutathione were determined as described in Materials and Methods.

cell lines (Figure 2 and data not shown), although the Seg-1 cells were less sensitive to apoptosis induction by exisulind than the Bic-1 and HCE7 cells. However, all three cell lines were equally sensitive to growth inhibition and apoptosis induction by CP248.

Cell-cycle analysis indicated that when these three esophageal cancer cell lines were treated with CP248 for $24 \mathrm{~h}$, there was a marked arrest of the cell cycle in $\mathrm{G} 2 / \mathrm{M}$, and a major fraction of the cells were specifically arrested in mitosis (Figures 3 and 4, Table 1, and data not shown). The ability of CP248 to induce G2/ $\mathrm{M}$ arrest has been previously seen in both prostate (6) and glioblastoma cell lines (14), and apparently reflects the ability of this compound to impair microtubule polymerization (14). On the other hand, exisulind did not have a significant effect on cell-cycle progression in our three esophageal cancer cell lines (Figure 3 and Table 1). In prostate cancer cells, exisulind induces partial arrest in the G1/S phase (6),

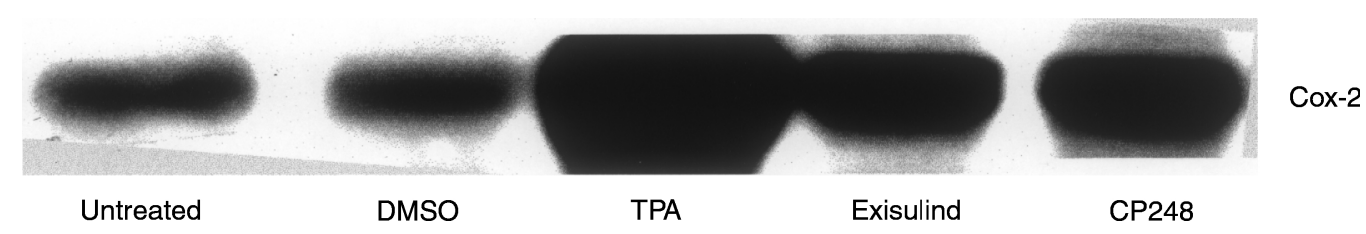

Figure 6. Cyclooxygenase-2 (cox-2) protein expression in Seg-1 esophageal cancer cells after treatment with $0.1 \%$ dimethylsulfoxide (DMSO), $100 \mathrm{ng} / \mathrm{ml} 12-0$-tetradeconoylphorbol-13-acetate (TPA), $300 \mu \mathrm{M}$ exisulind, or $200 \mathrm{nM} \mathrm{CP248.} \mathrm{After} 48 \mathrm{~h}$ of treatment, cell lysates were evaluated for cox-2 expression by Western blotting. 
but it does not induce significant arrest in any specific phase of the cell cycle in MCF7 breast cancer cells, glioma cells, or colon cancer cells, and it does not impair microtubule polymerization $(9,14)$ (and unpublished studies). The extremely potent effects of CP248 on growth inhibition and apoptosis in esophageal cancer cell lines seen in the present study may be due, at least in part, to its ability to arrest these cells in mitosis.

Soh et al., recently obtained evidence that induction of apoptosis in SW480 cells by exisulind, CP248, and related compounds was due, at least in part to PKG-mediated activation of JNK1 (12). Mechanistic studies in NIH-3T3 cells also established a novel pathway by which the activation of PKG leads to activation of JNK1 (13). These findings are consistent with previous evidence that JNK1, and other stress-activated protein kinases, play important roles in mediating cellular stress responses, including apoptosis, induced by other agents $(30,31)$. In the present study, we found that rapid activation of JNK1 also occurred in Seg-1 cells after treatment with exisulind or CP248, and with CP248, this activation was sustained for at least $24 \mathrm{~h}$ (Figure 5). Therefore, JNK1 activation probably also plays an important role in the induction of apoptosis by exisulind and CP248 in esophageal cancer cells.

GST and glutathione play important roles in carcinogen detoxification. GSH, an endogenous tripeptide thiol, functions as an antioxidant and protects cells from damage by free radicals, xenobiotic compounds, and other cellular toxins (29). The biologically active reduced form is readily measured using HPLC (23). When Seg-1 cells were treated with exisulind or CP248, within $3 \mathrm{~h}$ there was a moderate increase, and at $24 \mathrm{~h}$ a marked increase (about six-to eight-fold) in cellular levels of GSH (Figure 7). Similar results were seen with Bic-1 and HCE7 cells (data not shown). The mechanism responsible for this increase is unclear, but could reflect either an increase in de novo synthesis by gamma glutamyl synthetase or a decrease in cellular utilization of GSH. GSH induction has previously been seen with various NSAIDs (32) and garlic derivatives (33) and could contribute to the anticancer effects of these compounds. Compton et al. (34) found that levels of GST- $\pi$ mRNA and protein were lower in tissue samples of $\mathrm{BE}$ metaplasia than in normal esophageal mucosa. Decreased levels of this phase 2 detoxification enzyme may contribute to the increased susceptibility to carcinogenesis in this metaplastic tissue. Thus, our findings of GSH induction with exisulind and CP248 may provide an additional rationale for using these compounds as chemopreventive agents.

There is considerable current interest in the use of selective cox- 2 inhibitors as chemoprevention agents (35-37). Several types of evidence suggest that cox-2 plays an important role in the development of various gastrointestinal malignancies, including those of the esophagus, stomach, colorectum, liver, and pancreas $(24,25)$. An increase in the cox-2 protein has been detected in BE and BAA (27), as well as in esophageal high-grade dysplasia and esophageal squamous cell carcinoma (26). Selective cox- 2 inhibitors have been shown to reduce polyp development in FAP patients (37). Therefore, in the present study, we investigated the levels of cox-2 at baseline and after treatment with exisulind and CP248 in the three esophageal cancer cell lines. We found that the Seg-1 cells expressed a detectable basal level of cox-2 (Figure 6), but we could not detect cox-2 expression in either Bic-1 or HCE7 cells (data not shown). Although cox-2 mRNA was detected in $70-80 \%$ of $\mathrm{BE}$ and BAA tissue specimens, the frequency of cox- 2 protein expression in these samples was not reported (38). Therefore, it is not clear what proportion of $\mathrm{BE}$ lesions or BAA are likely to respond to selective cox-2 inhibitors. Surprisingly, we found that cox- 2 was actually induced by both exisulind and CP248 in Seg- 1 cells within $5 \mathrm{~h}$ of treatment, and was further induced after 24-48 h of treatment (Figure 6, and data not shown). The mechanism of this induction is not known. It was recently reported that microtubule-interfering agents, including colchicine and paclitaxel, induce cox-2 mRNA and protein in human mammary epithelial cells (39). This could explain the induction of cox-2 by CP248, since CP248 also disrupts microtubule assembly (14). On the other hand, exisulind also induced cox-2 expression in Seg-1 cells, and yet it does not cause mitotic arrest (Figure 3 and Table 1) or disrupt the 
cellular cytoskeleton (14). Cox-2 induction has also been reported during HIV-1 gp120induced apoptosis (40), generalized inflammation (41), and increased mechanical loading stress $(42,43)$. Therefore, the induction of cox- 2 by CP248 and exisulind in Seg- 1 cells may occur through nonspecific mechanisms. It is of interest that despite differences in basal levels of cox-2 expression, all three cell lines were sensitive to the antiproliferative effects of exisulind and CP248. Indeed, the cox-2-negative Bic-1 and HCE7 cells were more sensitive to the growth inhibitory and apoptosis-inducing effects of exisulind than the cox-2-positive Seg-1 cells. These findings provide further evidence that cox-2 is not the critical target for the antitumor effects of exisulind and CP248. They are also consistent with previous studies indicating that exisulind and CP248 do not inhibit the in vitro activities of cox- 1 or cox-2 $(5,6)$.

\section{CONCLUSION}

In summary, exisulind and CP248 inhibit growth and induce apoptosis in both BE-related adenocarcinoma and esophageal squamous carcinoma cells by a cox-2independent mechanism. Both compounds are very potent activators of JNK1. However, only CP248 can induce mitotic arrest and inhibit microtubule polymerization. This dual effect may explain the higher potency of CP248 when compared with that of exisulind. These compounds may therefore be useful in preventing the development of esophageal adenocarcinoma in patients with $\mathrm{BE}$ and, when used alone or in combination with other agents, in the treatment of patients with adenocarcinoma or squamous carcinoma of the esophagus. In clinical studies, assays for apoptosis, JNK1 activation, and GSH levels in tissue biopsy specimens may provide useful surrogate intermediate endpoints.

\section{ACKNOWLEDGEMENTS}

The authors thank Haim Shirin, Barbara M. Castro, and Steven W. Xing for valuable advice and assistance.
This work was supported in part by an American Association for Cancer Research-Cancer Research Foundation of America Fellowship in Prevention Research and awards from the T.J. Martell Foundation, the National Foundation for Cancer Research, and from Cell Pathways, Inc.

\section{REFERENCES}

1. Riddell RH. Early detection of neoplasia of the esophagus and gastroesophageal junction. Am $J$ Gastroenterol 91: 853-863, 1996.

2. Rusch VW, Levine DS, Haggitt R, Reid BJ. The management of high grade dysplasia and early cancer in Barrett's esophagus. A multidisciplinary problem. Cancer 74: 1225-1229, 1994.

3. Thun MJ, Namboodiri MM, Heath CW Jr. Aspirin use and reduced risk of fatal colon cancer. $N$ Engl $J$ Med 325: 1593-1596, 1991.

4. Goldberg Y, Nassif II, Pittas A, Tsai LL, Dynlacht BD, Rigas B, Shiff SJ. The anti-proliferative effect of sulindac and sulindac sulfide on HT-29 colon cancer cells: alterations in tumor suppressor and cell cycle-regulatory proteins. Oncogene, 12: 893-901, 1996.

5. Piazza GA, Alberts DS, Hixson LJ, et al. Sulindac sulfone inhibits azoxymethane-induced colon carcinogenesis in rats without reducing prostaglandin levels. Cancer Res 57: 29092915, 1997.

6. Lim JT, Piazza GA, Han EK, et al. Sulindac derivatives inhibit growth and induce apoptosis in human prostate cancer cell lines. Biochem Pharmacol 58: 1097-1107, 1999.

7. Piazza GA, Rahm AL, Krutzsch M, et al. Antineoplastic drugs sulindac sulfide and sulfone inhibit cell growth by inducing apoptosis. Cancer Res 55: 3110-3116, 1995.

8. Thompson HJ, Jiang C, Lu J, Mehta RG, Piazza GA, Paranka NS, Pamukcu R, Ahnen DJ. Sulfone metabolite of sulindac inhibits mammary carcinogenesis. Cancer Res 57: 267-271, 1997.

9. Han EK, Arber N, Yamamoto H, et al. Effects of sulindac and its metabolites on growth and apoptosis in human mammary epithelial and breast carcinoma cell lines. Breast Cancer Res Treat 48: 195-203, 1998.

10. Rahman MA, Dhar DK, Masunaga R, Yamanoi A, Kohno H, Nagasue N. Sulindac and exisulind exhibit a significant antiproliferative effect and induce apoptosis in human hepatocellular carcinoma cell lines. Cancer Res 60: 2085-2089, 2000.

11. Thompson WJ, Piazza GA, Li H, et al. Exisulind induction of apoptosis involves guanosine $3^{\prime}, 5^{\prime}$-cyclic monophosphate phosphodiesterase inhibition, protein kinase $\mathrm{G}$ activation, and attenuated beta-catenin. Cancer Res 60: 3338-3342, 2000.

12. Soh JW, Mao Y, Kim MG, Pamukcu R, Li H, Piazza GA, Thompson WJ, Weinstein IB. Cyclic GMP mediates apoptosis induced by sulindac derivatives via activation of $c$-Jun NH2-terminal kinase 1. Clin Cancer Res 6: 4136-4141, 2000.

13. Soh JW, Mao Y, Liu L, Thompson WJ, Pamukcu R, Weinstein IB. Protein kinase $G$ activates the JNK1 pathway via phosphorylation of MEKK1. J Biol Chem 276: 16406-16410, 2001.

14. Yoon J-T, Palazzo AF, Xiao D, et al. CP248, a derivative of Exisulind, causes growth inhibition, mitotic arrest and abnormalities in microtubule polymerization in glioma cells. Mol Cancer Ther 1: 393-404, 2002.

15. Goluboff ET, Shabsigh A, Saidi JA, et al. Exisulind (sulindac sulfone) suppresses growth of human prostate cancer in a 
nude mouse xenograft model by increasing apoptosis. Urology 53: 440-445, 1999.

16. van Stolk R, Stoner G, Hayton WL, et al. Phase I trial of exisulind (sulindac sulfone, FGN-1) as a chemopreventive agent in patients with familial adenomatous polyposis. Clin Cancer Res 6: 78-89, 2000.

17. Soriano AF, Helfrich B, Chan DC, Heasley LE, Bunn PA Jr, Chou TC. Synergistic effects of new chemopreventive agents and conventional cytotoxic agents against human lung cancer cell lines. Cancer Res 59: 6178-6184, 1999.

18. Banks-Schlegel SP, Quintero J. Growth and differentiation of human esophageal carcinoma cell lines. Cancer Res 46: 250-258, 1986.

19. Jiang W, Zhang YJ, Kahn SM, et al. Altered expression of the cyclin D1 and retinoblastoma genes in human esophageal cancer Proc Natl Acad Sci USA 90: 9026-9030, 1993.

20. Vermes I, Haanen $C$, Steffens-Nakken $H$, Reutelingsperger $C$. A novel assay for apoptosis. Flow cytometric detection of phosphatidylserine expression on early apoptotic cells using fluorescein labelled Annexin V. J Immunol Methods 184: 39-51, 1995.

21. Westendorf JM, Rao PN, Gerace L. Cloning of cDNAs for M-phase phosphoproteins recognized by the MPM2 monoclonal antibody and determination of the phosphorylated epitope. Proc Natl Acad Sci USA 91: 714-718, 1994.

22. Shirin $\mathrm{H}$, Sordillo EM, Oh SH, Yamamoto $H$, Delohery $T$, Weinstein IB, Moss SF. Helicobacter pylori inhibits the G1 to $S$ transition in AGS gastric epithelial cells. Cancer Res 59: 2277-2281, 1999.

23. Lakritz J, Plopper CG, Buckpitt AR. Validated highperformance liquid chromatography-electrochemical method for determination of glutathione and glutathione disulfide in small tissue samples. Anal Biochem 247: 63-68, 1997.

24. Eberhart CE, Coffey RJ, Radhika A, Giardiello FM, Ferrenbach S, DuBois RN. Up-regulation of cyclooxygenase 2 gene expression in human colorectal adenomas and adenocarcinomas. Gastroenterology 107: 1183-1188, 1994.

25. Ristimaki A, Honkanen N, Jankala H, Sipponen P, Harkonen M. Expression of cyclooxygenase-2 in human gastric carcinoma. Cancer Res 57: 1276-1280, 1997.

26. Shamma A, Yamamoto $H$, Doki $Y$, et al. Up-regulation of cyclooxygenase-2 in squamous carcinogenesis of the esophagus. Clin Cancer Res 6: 1229-1238, 2000.

27. Shirvani VN, Ouatu-Lascar R, Kaur BS, Omary MB, Triadafilopoulos G. Cyclooxygenase 2 expression in Barrett's esophagus and adenocarcinoma: Ex vivo induction by bile salts and acid exposure. Gastroenterology 118: 487-496, 2000.

28. Liu XH, Rose DP. Differential expression and regulation of cyclooxygenase- 1 and -2 in two human breast cancer cell lines. Cancer Res 56: 5125-5127, 1996.

29. Pinto JT, Rivlin RS. Antiproliferative effects of allium derivatives from garlic. J Nutr 131: 1058S-1060S, 2001.
30. Kyriakis JM, Banerjee P, Nikolakaki E, et al. The stressactivated protein kinase subfamily of c-Jun kinases. Nature 369: 156-160, 1994.

31. Chen YR, Wang W, Kong AN, Tan TH. Molecular mechanisms of c-Jun N-terminal kinase-mediated apoptosis induced by anticarcinogenic isothiocyanates. $J$ Biol Chem 273: 1769-1775, 1998.

32. van Lieshout EM, Tiemessen DM, Peters WH, Jansen JB. Effects of nonsteroidal anti-inflammatory drugs on glutathione S- transferases of the rat digestive tract. Carcinogenesis 18: 485-490, 1997.

33. Shirin H, Pinto JT, Kawabata Y, et al. Antiproliferative effects of S-allylmercaptocysteine on colon cancer cells when tested alone or in combination with sulindac sulfide. Cancer Res 61: 725-731, 2001.

34. Compton KR, Orringer MB, Beer DG. Induction of glutathione s-transferase-pi in Barrett's metaplasia and Barrett's adenocarcinoma cell lines. Mol Carcinog 24: 128-136, 1999.

35. Sharma RA. Translational medicine: targetting cyclo-oxygenase isozymes to prevent cancer. Q J M 95: 267-273, 2002.

36. Subbaramaiah K, Zakim D, Weksler BB, Dannenberg AJ. Inhibition of cyclooxygenase: a novel approach to cancer prevention. Proc Soc Exp Biol Med 216: 201-210, 1997.

37. Steinbach G, Lynch PM, Phillips RK, et al. The effect of celecoxib, a cyclooxygenase-2 inhibitor, in familial adenomatous polyposis. N Engl J Med 342: 1946-1952, 2000.

38. Wilson KT, Fu S, Ramanujam KS, Meltzer SJ. Increased expression of inducible nitric oxide synthase and cyclooxygenase-2 in Barrett's esophagus and associated adenocarcinomas. Cancer Res 58: 2929-2934, 1998.

39. Subbaramaiah K, Hart JC, Norton L, Dannenberg AJ. Microtubule-interfering agents stimulate the transcription of cyclooxygenase-2. Evidence for involvement of ERK $1 / 2$ AND p38 mitogen- activated protein kinase pathways. J Biol Chem 275: 14838-14845, 2000.

40. Corasaniti MT, Strongoli MC, Piccirilli S, et al. Apoptosis induced by gp120 in the neocortex of rat involves enhanced expression of cyclooxygenase type 2 and is prevented by NMDA receptor antagonists and by the 21-aminosteroid U-74389G. Biochem Biophys Res Commun 274: 664-669, 2000.

41. Gilroy DW, Colville-Nash PR. New insights into the role of COX 2 in inflammation. J Mol Med 78: 121-129, 2000.

42. Joldersma M, Klein-Nulend J, Oleksik AM, Heyligers IC, Burger EH. Estrogen enhances mechanical stress-induced prostaglandin production by bone cells from elderly women. Am J Physiol Endocrinol Metab 280: E436-E442, 2001.

43. Ogasawara A, Arakawa T, Kaneda T, Takuma T, Sato T, Kaneko H, Kumegawa M, Hakeda Y. Fluid shear stressinduced cyclooxygenase-2 expression is mediated by C/EBP beta, CAMP-response element-binding protein, and AP-1 in osteoblastic MC3T3-E1 cells. J Biol Chem 276: 7048-7054, 2001. 